\title{
Fighting by sleep-deprived rats as a possible manifestation of panic: effects of sodium lactate
}

F.A. Furlan ${ }^{1}$ and K. Hoshino ${ }^{2}$

\section{Correspondence \\ F.A. Furlan \\ Faculdade de Medicina \\ Universidade de M arília \\ Av. Higyno Muzzi Filho, 1001 \\ 17525-902 Marília, SP \\ Brasil \\ Fax: + 55-14-433-8961 \\ E-mail: furlan@laser.com.br}

Research supported by CAPES. Publication supported by FAPESP.

Received March 9, 2000 Accepted January 17, 2001

\author{
${ }^{1}$ Faculdade de M edicina, Universidade de Marília, Marília, SP, Brasil \\ 2Departamento de Ciências Biológicas, Faculdade de Ciências, \\ Universidade Estadual Paulista, Bauru, SP, Brasil
}

\section{Abstract}

Increased fighting is an effect of desynchronized sleep deprivation (DSD) in rats, and recently this behavior has been suggested to be spontaneous panic and equivalent to panic disorder. In the present study we tested this hypothesis by evaluating the effect of sodium lactate on this aggressiveness, because this substance is recognized to induce spontaneous panic attacks in patients. A total of 186 male albino Wistar rats, 250-350 g, 90-120 days of age, were submitted to DSD (multiple platform method) for 0,4 , or 5 days. At the end of the deprivation period the rats were divided into subgroups respectively injected intraperitoneally with $1.86,2.98$ and $3.72 \mathrm{~g} / \mathrm{kg}$ of $1 \mathrm{M}$ sodium lactate, or 1.86 and $3.72 \mathrm{~g} / \mathrm{kg}$ of $2 \mathrm{M}$ sodium lactate. The control animals were submitted to the same procedures but received equivalent injections of sodium chloride. Regardless of DSD time, sleepdeprived animals that received sodium lactate presented a significantly higher mean number of fights $(0.13 \pm 0.02$ fights $/ \mathrm{min})$ and a longer mean time spent in confrontation $(2.43 \pm 0.66 \mathrm{~s} / \mathrm{min})$ than the controls $(0.01 \pm 0.006$ fights $/ \mathrm{min}$ and $0.12 \pm 0.07 \mathrm{~s} / \mathrm{min}$, respectively; $\mathrm{P}<0.01$, Student $t$-test). For the sodium lactate group, concentration of the solution and time of deprivation increased the number of fights, with the mean number of fights and mean duration of fighting episodes being greater with the $2.98 \mathrm{~g} / \mathrm{kg}$ dose using $1 \mathrm{M}$ lactate concentration. These results support the hypothesis that fighting induced by DSD is probably a spontaneous panic manifestation. However, additional investigations are necessary in order to accept this as a promising animal model for studies on panic disorder.

\section{Introduction}

The homeotherm's sleep is composed of two phases that cycle alternately (1-3): synchronized sleep, divided into 4 stages and characterized by electroencephalographic waves of high voltage and low frequency, and desynchronized sleep, also character- ized by low voltage and high frequency waves, similar to the waves observed in the alert phase.

Desynchronized sleep deprivation (DSD), experimentally applied to determine its function, induces many physiological and behavioral alterations that include changes in body temperature (4), immunological suppression
Key words

- Rat

Sleep deprivation

- Sodium lactate 
(5), a reduction in psychomotor performance (6) and mnemonic performance (7), hyperphagia (8), and an increase in sexual activity (9). In rats, one of the effects of DSD is an increase in fighting behavior (10) which has been recognized as being of a defensive nature $(11,12)$. Data from our laboratory $(13,14)$ suggest that these agonistic behaviors are panic manifestations.

Panic is an explosive reaction characterized by a set of somatic and autonomic responses associated with intense fear. It has been suggested that panic is a phenomenon related to the "flight-or-fight" behavior (15), and is manifested when a stimulus, recognized as dangerous, approaches or touches the individual (situational panic). Nevertheless, panic-triggering mechanisms can suffer alterations and promote this behavior without justifiable environmental causes (spontaneous panic). This phenomenon has been described for some non-human animal species in both natural (16) and experimental situations (17-19). Frequent recurrence of spontaneous panic attacks in humans characterizes the behavioral abnormality named panic disorder (PD). Since some episodes of fighting induced by DSD occur without the animal being actually threatened (normally conspecifics do not represent a threatening stimulus in groups of rats), they are presumed to be a spontaneous panic manifestation.

In the present study we evaluated the effects of sodium lactate administration on the fighting behavior of rats submitted to DSD in order to test the validity of the hypothesis that they are panic manifestations. Lactate was chosen because it is known, since the classic work of Pitts and McClure (20), that the infusion of sodium lactate can precipitate panic attacks in patients with $\mathrm{PD}$. These panic attacks are symptomatically similar to those that occur naturally (21), and the response to lactate is currently considered to be a sensitive and specific marker for PD (22).

\section{Material and Methods}

A total of 186 male albino Wistar rats weighing 250-350 g and aged 90-120 days were used for the study. After a minimum period of 7 days for adaptation to the laboratory conditions, the animals were submitted to DSD for 0 (group DSD-0), 4 (group DSD4) or 5 (group DSD-5) days. Thirty minutes before the end of the DSD period, a large individual identification symbol was painted on the animal's neck or trunk with a black dye for human hair (Henne) routinely used in our laboratory (23). Sodium lactate or sodium chloride was then injected $i p$, and the animals were kept in wire-mesh cages $(25 \times 30 \times 25 \mathrm{~cm})$ in groups of 4 animals per experimental treatment. Similar control groups of 5 animals each were also studied. The total number of animals in each subgroup is presented together with the results.

The multiple platform method (23) was used for DSD. Ten rats were placed simultaneously in a plastic box $(105 \times 55 \times 27 \mathrm{~cm})$ containing 15 cylindrical platforms $(6 \mathrm{~cm}$ in height and $5 \mathrm{~cm}$ in diameter) fastened to the bottom of the box $15 \mathrm{~cm}$ apart from each other. The box was then filled with water up to $1 \mathrm{~cm}$ from the platform top. The animals kept on the platforms were able to sleep; however, when they reached the desynchronized sleep phase, the muscular atonia typical of this phase would cause their nose to touch the water or the animal would fall into the water and be awakened. Natural temperature and light/dark cycle conditions were used. Water and food were provided ad libitum throughout the DSD period.

Buffered sodium lactate solutions were used (CEAQUIM, Botucatu, SP, Brazil). Doses of 1.86, 2.98 and $3.72 \mathrm{~g} / \mathrm{kg}$, using a 1$\mathrm{M}$ solution, and doses of 1.86 and $3.72 \mathrm{~g} / \mathrm{kg}$ using a 2-M solution were tested. Since doses of 2.98 and $3.72 \mathrm{~g} / \mathrm{kg}$ required a large volume of solution to be injected, they were divided into 2 equal parts and applied with a 30-min interval. Control animals were simi- 
larly injected with saline. The behavior of the rats was filmed during a period of $60 \mathrm{~min}$ after the end of the injections. Later, the number and duration of fighting episodes were quantified, without considering the data acquired during the first $10 \mathrm{~min}$. Fighting behavior was considered to occur when two or more animals faced each other in a vertical position, noses elevated, front paws mutually touching ("boxing") or when an animal maintained the opponent immobilized (subjugation) in total or partial decubitus using its forepaws ("on the top/on the back").

The quantitative results are presented as percentages or as mean \pm SEM number of fighting episodes. The number of fights displayed by each animal was counted using the painted identification mark. When this was not possible, the video record was played back and reviewed as many times as necessary (generally in slow motion) for the identification of the animal involved in the agonistic confrontation. A "blind" observer computed the fighting parameters. However, he was able to discriminate some lactate-treated groups due to the conspicuous differences displayed by them. The fighting behavior of animals that showed seizures and died during the observation period was not computed. Data were analyzed statistically by the unpaired Student $t$-test or, when this test could not be used, by the Mann-Whitney Utest. In both cases, the differences were considered significant when $\mathrm{P}<0.05$.

\section{Results}

The injection of hypertonic lactate or sodium chloride induced defensive reactions indicating pain. This was characterized by vocalization, loss of natural posture, agitated licking of the abdominal region, and biting of the cage bars or of other animals in different sequences. These manifestations ceased during the first $5 \mathrm{~min}$. The animals that received sodium chloride progressively presented exploratory behavior intermittently interrupted by cleaning behaviors, and subsequently culminating in sleep. Some of the rats stayed awake and eventually confronted or awakened those that slept, and the latter, for the most part, merely looked for a new place to sleep. The animals that received sodium lactate showed similar behavior up to the 30th min, with little grooming behavior, when they initiated locomotor activity that lasted approximately $30 \mathrm{~min}$. Many animals showed a freezing behavior during this period: they would stay apart, yet attentive to a fixed point or to movement in the cage, sometimes supporting themselves on their hind paws, maintaining an arched dorso and the front paws partially extended ("freezing"). These animals readily responded to another approaching rat or to a visual stimulus, or to external sounds, by rapidly standing in a typical vertical defensive position and vocalizing, inducing a similar response in the animal nearby, and initiating a typical confrontation.

These agonistic behaviors, all characteristic of defense, were portrayed by vertical confrontations $(82.8 \%)$ or "on the top/on the back" subjugation (18.2\%). Vertical confrontations involved $2(71.1 \%), 3(18.6 \%)$ or rarely more animals $(0.3 \%)$. In some cases, both vertical confrontations and subjugations occurred with one animal jumping on others (one or more).

The rats from the DSD-0 group did not fight. The number of rats that showed fighting behavior was greater in the groups treated with lactate $(53.9 \pm 13.51 \%)$ than in control groups $(7.80 \pm 5.75 \%)(\mathrm{P}<0.01$, Student $t$-test). The mean number of fights per minute and the mean time spent in confrontations per minute were also significantly greater for the experimental animals (Figures 1 and 2).

The effect of sodium lactate in increasing fighting behavior induced by DSD was overall more evident for the DSD-5 animals and the most effective concentration was $1 \mathrm{M}$. The lactate dose that induced the highest 
mean number of fights with the longest duration was $2.98 \mathrm{~g} / \mathrm{kg}$. The highest doses of lactate and sodium chloride $(3.72 \mathrm{~g} / \mathrm{kg}$ of 2 $\mathrm{M}$ solutions) induced a behavioral depression, followed by tremors, "wild running" and spontaneous convulsions in 20 rats, which eventually ended in death.

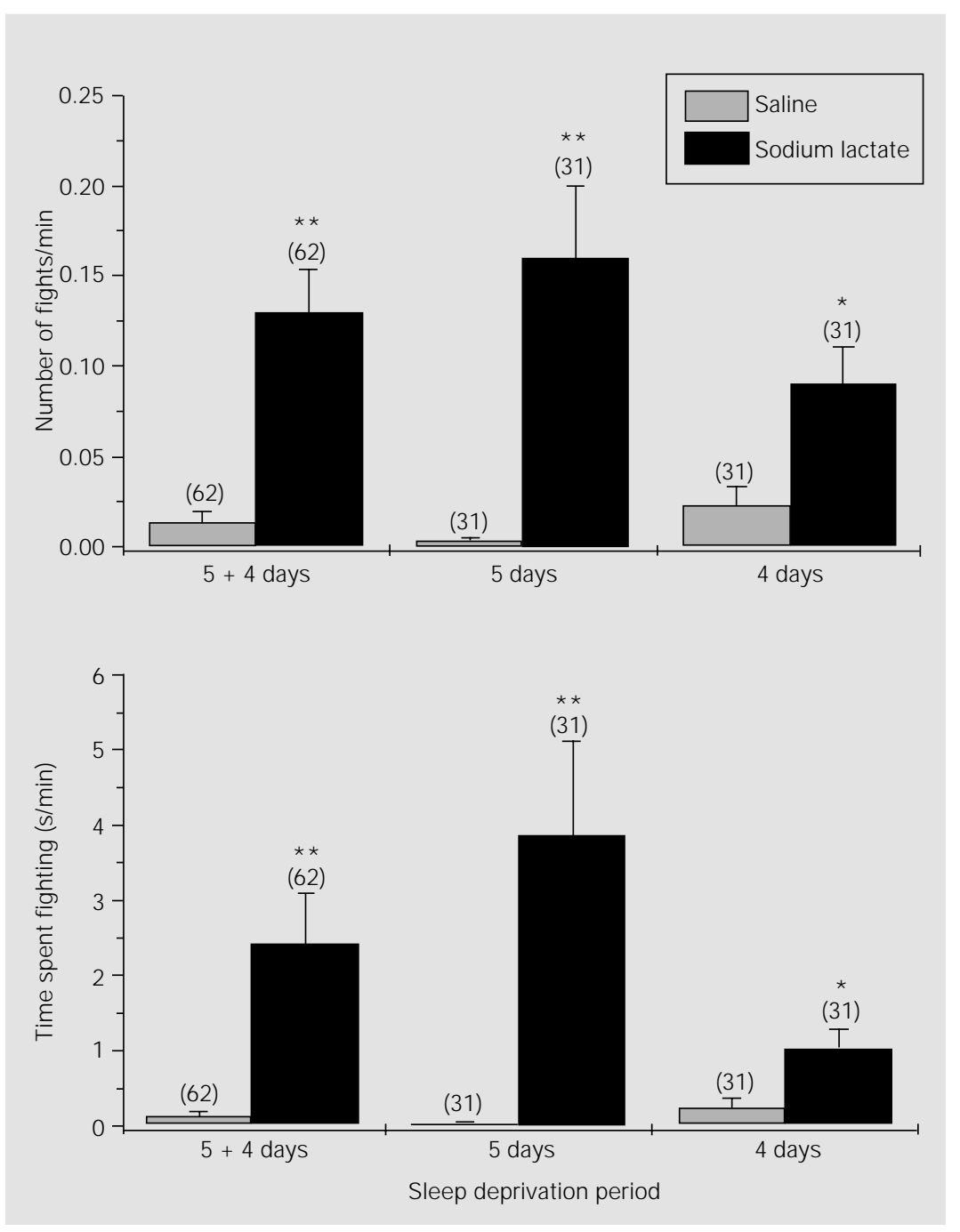

Figure 1 - Fighting in sleep-deprived rats after lactate administration. Mean ( \pm SEM) number of fights per minute (upper graph) and time spent fighting per minute (lower graph) as a function of deprivation of desynchronized sleep time in rats that received sodium lactate solutions (black columns) or $\mathrm{NaCl}$ (gray columns), independent of the concentration or dosages of these solutions. The period of deprivation $5+4$ (left columns) represents the combination of data obtained from sleep deprivation days 5 (center columns) and 4 (right columns). The number of animals is shown in parentheses above the bars for each group. $* \mathrm{P}<0.05$ and $* * \mathrm{P}<0.01$ for the comparison of sodium lactate vs saline during the same deprivation period (Student t-test).

\section{Discussion}

The main results obtained in the present study show that the administration of sodium lactate to rats significantly increases the number and duration of fights induced by sleep deprivation. This result supports the hypothesis that these fights might be manifestations of panic, since lactate administration, as mentioned before, precipitates panic attacks in PD patients. Such interpretation is supported by studies (13) addressing fighting induced by electrical shocks applied to the paws, which is quite similar to that observed in sleep-deprived rats, as well as panic. Ethological analysis to determine how fighting episodes start in DSD rats (13) has shown that the agonistic behavior is displayed only by those that quit self-cleaning and exhibit longer periods of behavioral freezing when removed from the deprivation cage, as seen in the present study. Freezing reactions, characterized by spontaneous movement arrest, hypertonic posture, and tremor, are indicative of extreme anxiety. Their occurrence in fighting DSD rats suggests a relationship between fighting and anxiety disorders. As seen before, an animal in a freezing posture shifts to the upright position in response to watchful stimuli (conspecific approach, acoustic stimuli, etc., although $20 \%$ start this behavior with no detectable environmental stimuli (13)), thereby inducing a similar response in nearby animals followed by confrontation. Since no attempts to attack are seen during long-lasting confrontations, this may be interpreted as defensive behavior. Confrontation may also start when a behaviorally frozen DSD animal, startled by a sudden conspecific shriek or other stimuli, triggers an episode of "wild running" flight. In this case, collision with mates generally induces confrontation simultaneously in two or more animals, often determining the "on the top/on the back" pattern of fighting, either because time is not enough to complete uprighting or because animals lose their bal- 
ance. The present classification of this confrontation pattern - which accounts for almost $20 \%$ of fighting episodes - as defensive seems to be correct since the characteristic bite threats aimed at the dorsal part of the opponent are absent, as is the characteristic tail rattling exhibited during offensive aggressiveness. The classification by Adams (24) is similar. In our previous study (12) of 139 DSD-induced fighting episodes, 105 proved to be defensive, whereas only three proved to be offensive using the criteria described in the literature (24-26). Defensive patterns of fighting in rats may be associated with panic $(19,27,28)$, and hyperdefensive fighting and flights induced in rats by intravenous administration of cocaine have been recently considered to be panic-like manifestations (29). On the basis of these considerations, it seems possible to interpret DSD-induced fighting as a manifestation of panic.

A parallel study in our laboratory (30) has shown that fighting after DSD is displayed only by rats that respond with "wild running" flight to intense auditory stimulation in individual test chambers. This "wild running" flight response has also been shown to be facilitated by DSD and lactate administration, and impaired by imipramine administration. Since this kind of flight is recognized as a manifestation of panic $(28,29)$, the fighting behavior of DSD may be considered as the expression of the flight-or-fight response, which in turn is considered to be an expression of panic-related antipredatory defense $(15,27)$.

Sleep disturbances in PD sufferers have been reported to be a consequence of anxiety disorders (31). The hypothesis that sleep deprivation may provoke panic manifestations has been raised, with little emphasis, by Milasius et al. (32) for rabbits and by Labbate et al. (33) for humans, prior to experimental evidence obtained by our group $(13,14)$ showing a significant reduction of fighting in DSD rats by fluoxetine. In agree- ment with these data, it has been documented that sleep deprivation increases panic symptoms in PD patients (34), who show increased partial pressure of $\mathrm{CO}_{2}(35)$, a condition recognized as being panicogenic (36).

Although the above considerations sup-

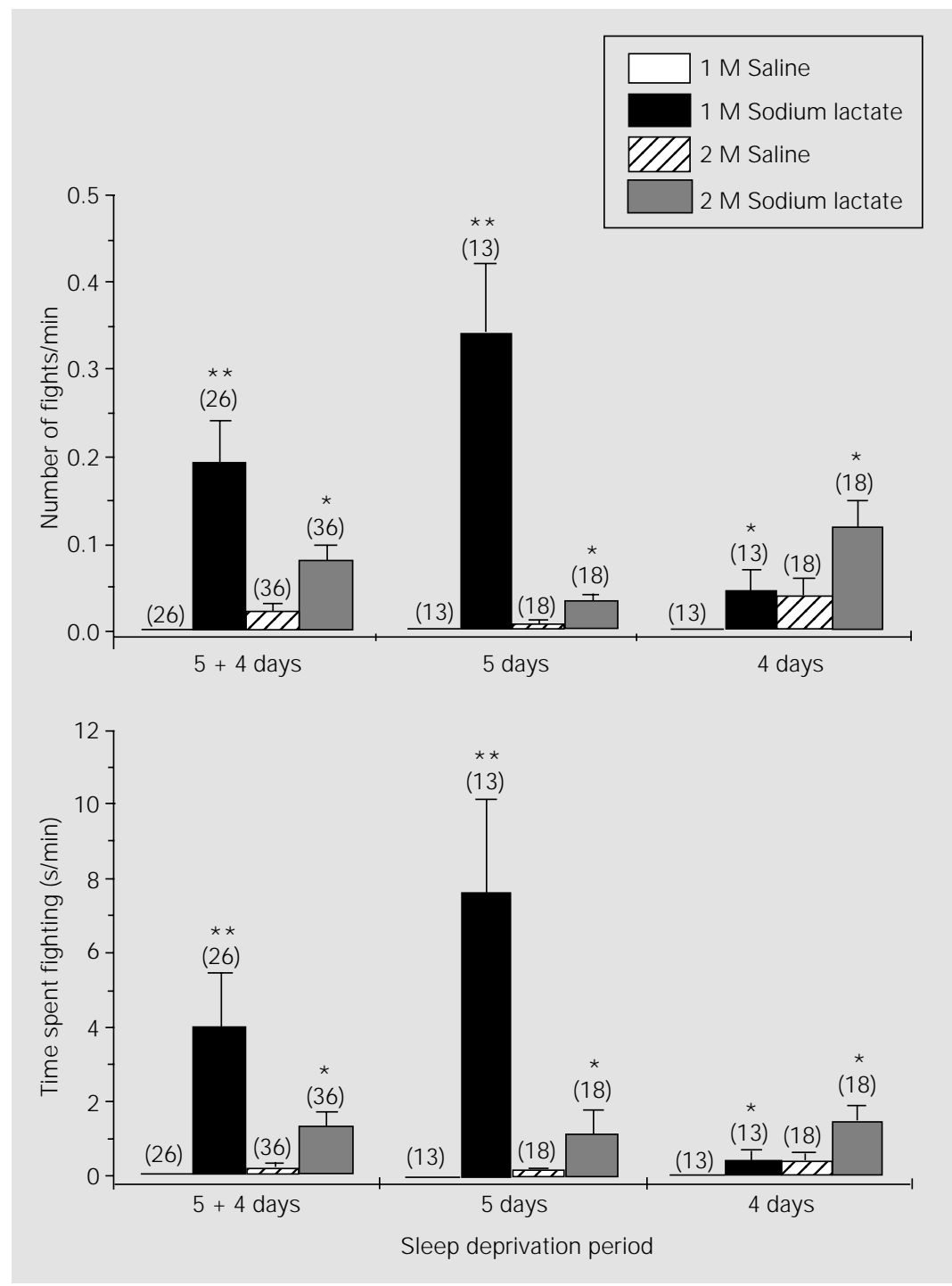

Figure 2 - Fighting in sleep-deprived rats after lactate administration. Mean ( \pm SEM) number of fights per minute (upper graph) and time spent fighting per minute (lower graph) as a function of deprivation of desynchronized sleep time in rats that received sodium lactate solutions (black and gray columns) or $\mathrm{NaCl}$ (white and striped columns). The period of deprivation $5+4$ (left columns) represents the combination of data obtained from sleep deprivation days 5 (center columns) and 4 (right columns). The number of animals is shown in parentheses above the bars of each group. $* \mathrm{P}<0.05$ and $* * \mathrm{P}<0.01$ for the comparison of sodium lactate vs saline with similar concentrations and within the same deprivation period (Mann-Whitney U-test for the comparison of groups receiving 1-M solutions; Student t-test for the comparison of groups receiving 2-M solutions). 
port our conclusion that fighting after DSD possibly is a panic manifestation, sleep deprivation does not seem to be the main determinant cause, since not all sleep-deprived animals fight. Increased neuronal excitability resulting from DSD has been known since earlier investigations on the subject (37) and may be the facilitating factor in the main central panicogenic mechanism. What such mechanism is, however, is still unknown. Panic manifestations are concomitant with intense fear or terror and this emotional experience is abolished after bilateral excision of the temporal lobes (Klüver-Bucy syndrome). The amygdala nuclei, located in the temporal lobe, have been shown to be involved in the etiology of panic in humans (38). Fighting behavior is elicited in rats by experimental manipulations of the amygdala nuclei (15) and lactate and DSD may exert their facilitating action on these temporal lobe structures that permit a relation between panic and fighting. Determination of the role played by such nuclei in DSD fighting seems to be the next important step for our line of investigation.

The possibility that lactate increases panic in sleep-deprived animals appears to have an important adaptive function under natural conditions since panic is an emotional response associated with defensive behavior patterns $(15,27)$. The concentration of endogenous lactate - derived from the lactic acid of the anaerobic glycolysis - increases in high energy-demanding situations and fatigue. By triggering panic which enhances the defensive responses of fight or flight, lactate seems to provide the best conditions for the ultimate efforts to preserve life. Of all the numerous hypotheses proposed during the last 30 years for the mechanism of action of lactate (39), none has proved to be satisfactory (40). Nevertheless, lactate facilitation, along with the enhanced neural excit- ability promoted by DSD, can explain the increase in the number and duration of panic fights when panic-sensitive animals are deprived of sleep and given lactate. The occurrence of seizures sometimes followed by death when higher doses are used seems to be a natural sequence of the increasing intensity of panic-inducing stimuli (30). Such manifestations are not seen clinically because lactate is administered continuously and discontinued when the highest safe dose is reached. Since continuous administration was difficult in the conditions of the present experiment, a fixed dose was given in one or two injections.

As mentioned before, lactate administration induces panic manifestations in PD patients. The lactate-induced increase in fighting in DSD rats raises the question whether this behavioral manifestation in laboratory animals is equivalent to that seen in humans, and, by extension, whether it is possible to use it as an experimental model for PD. DSD-induced fighting fulfills some predictive and face validity criteria (many fighting episodes start without detectable stimuli, fluoxetine reduces fighting, and lactate increases it); however, many neurochemical and neurophysiological parameters need to be investigated in order to establish it as a reliable model of PD. In fact, the platform method used to promote DSD involves stress and fatigue (23). Panic fighting by DSD rats may be ascribed to stress or to demodulation resulting from excessive fatigue.

Finally, it may be stated that, although further investigation is needed to clarify a number of aspects of DSD-induced fighting, our data seem important because they raise the interesting possibility of evaluating some cases of domestic violence and social aggression as a result of panic attacks, probably precipitated by sleep deprivation and other contingencies. 


\section{References}

1. Aserinsky E \& Kleitman N (1953). Regularly occurring periods of eye motility, and concomitant phenomena, during sleep. Science, 118: 273-274.

2. Dement W \& Kleitman N (1957). Cyclic variations in EEG during sleep and their relation to eye movements, body motility and dreaming. Electroencephalography and Clinical Neurophysiology, 10: 291296.

3. Timo-laria $C$, Negrão $N$, Schmidek WR, Hoshino K, Menezes CEL \& Rocha CL (1970). Phases and states of sleep in the rat. Physiology and Behavior, 5: 10571062.

4. Hoshino K (1996). Food deprivation and hypothermia in desynchronized sleep-deprived rats. Brazilian J ournal of Medical and Biological Research, 29: 41-46.

5. Kubo $C$, Sogawa $H$, Teshima $H \&$ Nakagawa T (1992). The effects of starvation and sleep deprivation on the immunological functions. J apanese J ournal of Psychosomatic Medicine, 32: 13-20.

6. Kleitman N (1963). Sleep and Wakefulness. The University of Chicago Press, Chicago.

7. Fishbein W \& Gutwein BM (1977). Paradoxical sleep and memory storage processes. Behavioral Biology, 19: 425-464.

8. Everson CA (1995). Functional consequences of sustained sleep deprivation in the rat. Behavioural Brain Research, 69: 43-54.

9. Morden $\mathrm{B}$, Mullens $\mathrm{R}$, Levine $\mathrm{S}$, Cohen $\mathrm{H}$ \& Dement W (1968). Effect of REM sleep deprivation on the mating behavior of male rats. Psychophysiology, 5: 241 (Abstract).

10. Tufik S, Lindsey CJ \& Carlini EA (1978). Does REM sleep deprivation induce a supersensitivity of dopaminergic receptor in the rat brain? Pharmacology, 16: 98-105.

11. Sandrin MFN (1996). Sono de ratos confinados em alta densidade populacional. Master's thesis, UNESP, Botucatu, SP, Brazil.

12. Sandrin MFN \& Hoshino K (1999). Agressividade em ratos privados de sono: caracterização etológica dos confrontos agonísticos como padrões de comportamento defensivo. Revista de Etologia, 1: 9-18.

13. Medeiros-Santille R (1998). Definição da agressividade induzida pela privação de sono na plataforma múltipla como manifestação de pânico no rato albino macho. Doctoral thesis, UNESP, Botucatu, SP, Brazil.
14. Hoshino K, Sandrin MFN, Medeiros R, Lenneberg-Hoshino C \& Tufik S (1998). Comportamento de pânico e generalização de brigas em ratos privados de sono. Annals of the XIII Annual Meeting of the Federação de Sociedades de Biologia Experimental, Caxambu, MG, Brazil, August 26-29, 58-59.

15. Graeff FG (1994). Neuroanatomy and neurotransmitter regulation of defensive behaviors and related emotions in mammals. Brazilian J ournal of Medical and Biological Research, 27: 811-829.

16. Chertok L \& Fontaine M (1965). Introduction à une clinique psychosomatique véterinaire. In: Psychiatric Animale Deselee. Brouwer, Paris apud Medeiros-Santille R (1998). Definição da agressividade induzida pela privação de sono na plataforma múltipla como manifestação de pânico no rato albino macho. Doctoral thesis, UNESP, Botucatu, SP, Brazil.

17. J enck F, Broekkamp CLE \& Van Delft AML (1988). Serotonergic drugs on the panic response elicited by periaqueductal gray simulation in rats. Psychopharmacology, 96 (Suppl): 236 (Abstract).

18. Deakin J FW \& Graeff FG (1991). 5-HT and mechanisms of defense. J ournal of Psychopharmacology, 5: 305-315.

19. Graeff FG (1991). Neurotransmitters in the dorsal periaqueductal gray and animal models of panic anxiety. In: Briley $M$ \& File SE (Editors), New Concepts in Anxiety. CRC Press, New York, 288-307.

20. Pitts FM \& McClure JN (1967). Lactate metabolism in anxiety neurosis. New England J ournal of Medicine, 277: 1329-1336.

21. Liebowitz MR, Fyer AJ, Gorman JM, Dillon D, Appleby IL, Levy G, Anderson S, Levitt $M$, Palij M, Davies SO \& Klein DF (1984). Lactate provocation of panic attacks. I. Clinical and behavioral findings. Archives of General Psychiatry, 41: 764770.

22. Cowley DS \& Arana GW (1990). The diagnostic utility of lactate sensitivity in panic disorder. Archives of General Psychiatry, 47: 277-284.

23. Medeiros R, Lenneberg-Hoshino C, Hoshino K \& Tufik S (1998). Neuroethologic differences in sleep deprivation induced by the single- and multiple-platform methods. Brazilian J ournal of Medical and Biological Research, 31: 675-680.

24. Adams DB (1980). Motivational systems of agonistic behavior in muroid rodents: comparative review and neural model. Aggressive Behavior, 6: 295-346.
25. Eibl-Eibsfeldt I (1961). The fighting behavior of animals. Scientific American, 105: 112-122.

26. Blanchard RJ \& Blanchard DC (1990). An ethoexperimental approach to the study of aggression. In: Morato S, Carobrez AP $\&$ Lima TCM (Editors), Neurosciences and Behavior. Faculdade de Filosofia, Ciências e Letras de Ribeirão Preto, Ribeirão Preto, SP, Brazil, 107-124.

27. Graeff $F G$, Silveira MCL, Nogueira RL, Audi EA \& Oliveira RMW (1993). Role of the amygdala and periaqueductal gray in anxiety and panic. Behavioural Brain Research, 58: 123-131.

28. Griebel G, Blanchard DC \& Blanchard RJ (1996). Predator-elicited flight responses in Swiss-Webster mice: an experimental model of panic attacks. Progress in NeuroPsychopharmacology and Biological Psychiatry, 20: 185-205.

29. Hebert MA, Blanchard DC \& Blanchard RJ (1999). Intravenous cocaine precipitates panic-like flight responses and lasting hyperdefensiveness in laboratory rats. Pharmacology, Biochemistry and Behavior, 63: 349-360.

30. Paula HMG (1999). Comportamento de defesa antipredatória: possível participação de mecanismos neurais convulsivos na etiologia das manifestações de pânico. Master's thesis, UNESP, Botucatu, SP, Brazil.

31. Culebras A (1996). Clinical Handbook of Sleep Disorders. Butterworth-Heinemann, Boston.

32. Milasius AM, Grinevicius K-KA \& Lapin IP (1990). Effect of quinolinic acid on wakefulness and sleep in the rabbit. J ournal of Neural Transmission, 82: 67-73.

33. Labbate LA, J ohnson MR, Lydiard RB, Brawman-M intzer O, Emmanuel N, Crawford M, Kapp R \& Ballenger J C (1997). Sleep deprivation in panic disorder and obsessive-compulsive disorder. Canadian J ournal of Psychiatry, 42: 982-983.

34. Roy-Byrne PP, Uhde TW \& Post RM (1986). Effects of one night's sleep deprivation on mood and behavior in patients with panic disorder: comparison with depressed patients and normal controls. Archives of General Psychiatry, 43: 895-899.

35. Craske MG \& Barlow DH (1990). Nocturnal panic: response to hyperventilation and carbon dioxide challenges. J ournal of Abnormal Psychology, 99: 302-307.

36. Gorman J M, Fyer MR, Goetz R, Askanazi J, Liebowitz MR, Fyer AJ , Kinney J \& Klein DF (1988). Ventilatory physiology of 
patients with panic disorder. Archives of General Psychiatry, 45: 31-39.

37. Hoshino K (1972). Perturbações motoras induzidas pela lesão eletrolítica da formação reticular mesencefálica em ratos privados de sono paradoxal. Doctoral thesis, UNESP, Botucatu, SP, Brazil.
38. Shekhar A, Sajdyk TS, Keim SR, Yoder KK \& Sanders SK (1999). Role of the basolateral amygdala in panic disorder. Annals of the New York Academy of Sciences, 877: 747-750.

39. Nutt D \& Lawson C (1992). Panic attacks: a neurochemical overview of models and mechanisms. British J ournal of Psychiatry, 160: 165-178.

40. Bourin M, Baker GB \& Bradwejn J (1998). Neurobiology of panic disorder. J ournal of Psychosomatic Research, 44: 163-180. 